\title{
UTILIZAÇÃO DO MÉTODO COLORIMÉTRICO PARA IDENTIFICAÇÃO DA REAÇÃO ÁLCALI-AGREGADO EM AMOSTRAS DE CONCRETO NO DISTRITO FEDERAL
}

\author{
SOARES, BRUNO \\ Engenheiro Civil \\ Universidade Católica de Brasília \\ Distrito Federal; Brasil \\ eng.brunoleobas@gmail.com
}

\section{RESUMO}

A reação álcali-agregado (RAA) é uma reação entre o agregado e os álcalis do cimento que gera um processo expansivo com o "gel" formado e causa fissuração desordenada em estruturas de concreto. Essa reação tem causado inúmeros problemas estruturais em diversos países pelo mundo, por esse fato cada vez mais tem chamado atenção de pesquisadores do mundo inteiro que buscam analisar o comportamento complexo dessa reação. Nesse contexto, esse artigo busca avaliar a presença da reação álcali-agregado em amostras de concreto do Distrito Federal, foram coletas amostras de concreto em 27 estruturas do Distrito Federal e para avaliar a presença da RAA foi utilizado um método colorimétrico, de caráter qualitativo, que consiste no uso de reagentes que em contato com o concreto formam tonalidades típicas em que é possível constatar a reação álcali-agregado. Foi utilizado também para constatação da RAA o Microscópio Eletrônico de Varredura (MEV) em 3 amostras de concreto das 27 coletadas para fazer uma comparação com o método colorimétrico, buscando avaliar as vantagens e desvantagens da utilização do método colorimétrico.

Palavras-chave: Reação álcali-agregado. Reatividade. Método colorimétrico. Concreto.

\section{ABSTRACT}

The alkali-aggregate reaction (AAR) is a reaction between the aggregate and alkalis of the cement that result an expansive process with the formed gel and causes disordered cracking in concrete structures. This reaction has caused numerous structural problems in several countries around the world, by this fact has increasingly attracted attention from researchers around the world that seek to assess the complex behavior of this reaction. In this regard, this article sought to evaluate the presence of the alkali-aggregate reaction in concrete specimen of the Federal District, specimen of concrete was collected in 27 structures of Federal District and a qualitative colorimetric method was used to evaluate the presence of RAA. This colorimetric method consists in use of reagents that in contact with the concrete form typical tonalities in which it is possible to verify the alkali-aggregate reaction. It was also used to verify the AAR the Scanning Electronic Microscope (SEM) in 3 concrete specimens of the 27 collected to make a comparison with the colorimetric method, seeking to evaluate the advantages and disadvantages of using the colorimetric method.

Keywords: Alkali-aggregate Reaction. Reactivity. Colorimetric method. Concrete. 


\section{INTRODUÇÃO}

Há alguns anos vem aumentando a quantidade de estruturas de concreto com manifestações patológicas sendo as mais comuns relacionadas a corrosão das armaduras por ataque de cloretos e de sulfatos no concreto (HELENE, 2003), há também algumas patologias que têm ganhado atenção de pesquisadores em todo o mundo por serem altamente destrutivas e se não tratadas adequadamente são de difícil recuperação estrutural. A manifestação patológica em questão é a reação álcali-agregado, que já foi considerada o "câncer" do concreto (COLLINS, 2007).

A reação álcali-agregado (RAA) foi observada primeiramente na América do Norte durante a década de $30 \mathrm{e}$ identificado pelo pesquisador Stanton em Dezembro de 1940. Stanton investigou a ocorrência de expansão e fissuras em pavimento de concreto na Califórnia, e descobriu que o problema foi causado devido aos componentes minerais presentes nos agregados. (STANTON, 1940).

O livro "Alkali-Aggregate Reaction Concrete: A World Review" traz relatos globais dos problemas causados pela reação álcali-agregado em diversos países. E de que forma as pesquisas de Stanton influenciaram nos estudos das causas da RAA.

Desde esse trabalho inicial, um enorme volume de pesquisas sobre causas, efeitos e possíveis soluções para o problema da RAA no concreto foi realizado. Esse trabalho foi impulsionado em parte pelos principais custos envolvidos em reparar os danos causados pela RAA, mas também pela extensão mundial do problema. (SIMS; POOLE; 2017).

A RAA, basicamente, é uma reação química entre os álcalis presente no cimento com alguns tipos de agregados reativos na presença de água. Há três tipos conhecidos de reação álcali-agregado, que são: a reação álcali-sílica (RAS), reação álcali-silicato (RSS) e reação álcali-carbonato (RAC). Na primeira, ocorre uma reação entre a sílica presente no agregado reativo com os álcalis do cimento $\left(\mathrm{Na}_{2} \mathrm{O}\right.$ e $\left.\mathrm{K}_{2} \mathrm{O}\right)$. Já na reação álcali-silicato, há reação entre alguns tipos de silicatos presentes em rochas sedimentares, metamórficas ou ígneas com os álcalis presentes no cimento. E por fim, na RAC ocorre uma interação entre os álcalis do cimento e as dolomitas presentes no calcário, formando a brucita $\left[\mathrm{Mg}(\mathrm{OH})_{2}\right]$, processo conhecido como "desdolomitização". É possível verificar características comuns a reação álcaliagregado como, por exemplo, fissurações do tipo "mapa", exsudação do gel formado, bordas brancas ao redor do agregado, preenchimento do poro com material esbranquiçado, microfissuração e descoloração do concreto (HASPARYK, 2005). As fotos abaixo exemplificam como essas características se manifestam no concreto.

Figura 1 - Fundação com fissuração tipo "mapa" do Ed. Areia Branca em Recife.

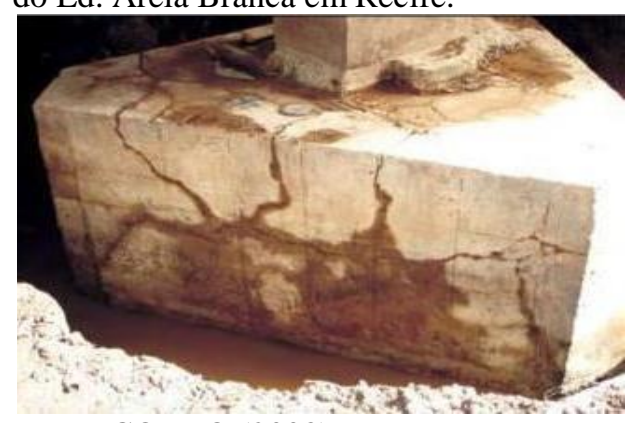

Fonte: COUTO (2008)

Figura 3 - Agregados graúdos com reação nas bordas

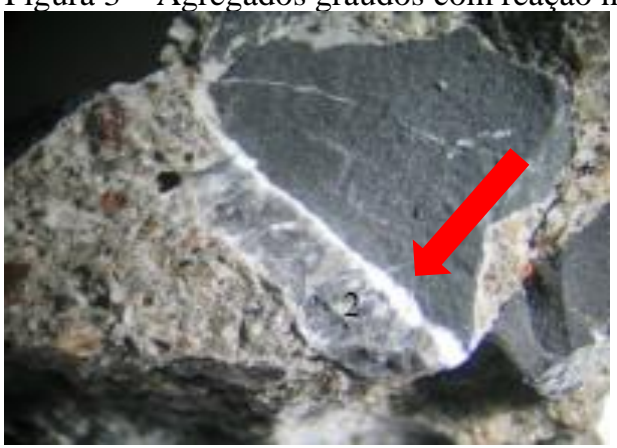

Fonte: SILVEIRA (2006)
Figura 2 - Eflorescência e exsudação do gel.

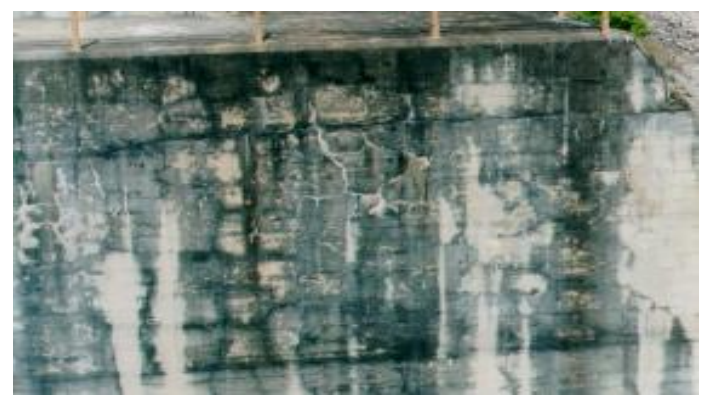

Fonte: SILVEIRA (2006)

Figura 4 - Poros com material esbranquiçado.

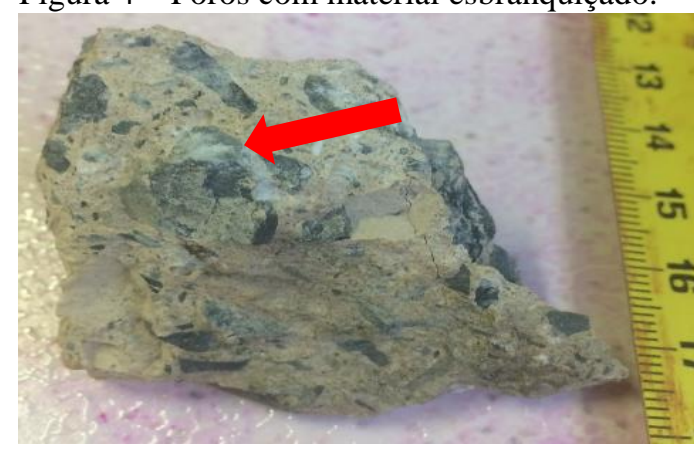

Fonte: Próprio Autor (2019) 
As estruturas de concreto armado em geral estão sujeitas a inúmeras manifestações patológicas principalmente quando estão expostas a umidade e que podem causar reações deletérias que afetam a durabilidade das estruturas. Neste contexto, uma das manifestações que diminui a vida útil das estruturas é a reação álcali-agregado (RAA), que causa fissuração desordenada e tem comportamento químico complexo na formação do gel expansivo resultado da reação.

Há anos tem se desenvolvidos inúmeras metodologias para diagnóstico da RAA, de modo que se tenha uma constatação qualitativa da reação. Guthrie e Carey (1999) patentearam um método colorimétrico, conhecido como método da mancha, que facilita a identificação da RAA em amostras de concreto com a aplicação de reagentes químicos em campo que confirmam a presença da reação pelas colorações produzidas pelos reagentes. Há outros métodos colorimétricos de avaliação da RAA:

1- Método do acetado de uranila: consiste na identificação da RAA pelo íon uranila, que em função da sua propriedade de fluorescência na presença de luz ultravioleta, forma colorações típicas.

2- Método de sufato de cupramônio: ocorre uma reação química entre o sulfato de cupramônio com componentes do concreto formando um composto de cor azul.

Entretanto, esses métodos apresentam deficiências em relação ao método da mancha pois tem aplicação em campo limitada, o método de sulfato de cupramônio não apresentam distinção característica do gel como no método da mancha e no método do acetado de uranila há utilização materiais radioativos (solução de urânio) (MIZUMOTO, 2009).

Essa pesquisa tem como objetivo geral avaliar a presença da reação álcali-agregado em amostras de concreto de diversas obras do Distrito Federal, com intuito de constatar se as manifestações patológicas dessas estruturas são causadas pela RAA.

Já nos objetivos específicos, essa pesquisa busca avaliar a presença do gel exsudado, produto formado na RAA, usando o método colorimétrico em amostras de concreto e verificar o comportamento desse método quanto ao uso para determinação da RAA.

\section{MATERIAIS E MÉTODOS}

Esse trabalho buscou avaliar a presença da reação álcali-agregado em inúmeras amostras coletadas em obras do Distrito Federal, com o uso do método colorimétrico que usam dois reagentes para confirmar a ocorrência de RAA nessas amostras.

\subsection{Materiais}

\subsubsection{Amostras de Concreto em Construções no DF}

Foram coletadas 26 amostras de concreto em diversas construções de todo o Distrito Federal. As amostras foram coletas utilizando um martelo, um ponteiro e uma furadeira de impacto, principalmente em estruturas expostas à ação da água. Este processo de retirada das amostras foi um ensaio destrutivo pois para esse trabalho era necessário levar as amostras para laboratório para fazer realizar todos os ensaios necessários, mas o método colorimétrico pode ser realizado in loco e é um ensaio não-destrutivo. Os principais locais com amostras coletadas foram obras abandonadas de edifícios, fábricas, hotéis, pontes e viadutos do DF que sofrem com a falta de manutenção e com a forte incidência de chuvas na região e que podem possivelmente apresentar reação álcali-agregado em suas estruturas.

\subsubsection{Reagente I: Cobaltonitrito de sódio}

O reagente cobaltonitrito de sódio é utilizado como reagente colorimétrico devido a sua capacidade de identificar a presença de potássio. Para a identificação da RAA, ocorre uma reação química entre os íons de potássio presentes no gel da reação, resultando em um precipitado amarelo (cobaltonitrito de potássio). O reagente Cobaltonitrito de Sódio utilizado é da marca Êxodo Científica e com grau de pureza P.A ACS ). Como mostram as equações abaixo:

$\mathrm{Na}_{3}\left[\mathrm{Co}\left(\mathrm{NO}_{2}\right)_{6}\right]+3 \mathrm{~K}^{+} \rightarrow \mathrm{K}_{3}\left[\mathrm{Co}\left(\mathrm{NO}_{2}\right)_{6}\right]+3 \mathrm{Na}^{+}$

(MIZUMOTO, 2009)

$$
\mathrm{Na}_{3}\left[\mathrm{Co}\left(\mathrm{NO}_{2}\right)_{6}\right]+2 \mathrm{~K}^{+} \rightarrow \mathrm{K}_{2} \mathrm{Na}\left[\mathrm{Co}\left(\mathrm{NO}_{2}\right)_{6}\right]+2 \mathrm{Na}^{+}
$$

\subsubsection{Reagente II: Rodamina B}

Após a impregnação com o primeiro reagente para identificar o gel resultante da reação, foi utilizado a Rodamina B que é um corante que interage quimicamente com as porções de cálcio presentes no gel, resultando em um composto de tonalidade rósea. O reagente Rodamina B utilizado é da marca Neon e tem grau de pureza classificado com P.A.

Ocorre um alto contraste de cores na amostra já impregnada com o reagente 1 , sendo possível determinar com precisão as regiões onde ocorre o processo de reação álcali-agregado (MIZUMOTO, 2009). 


\subsection{Métodos}

A partir dos conhecimentos à respeito do mecanismo da reação álcali-agregado e conhecendo as condições possíveis para a ocorrência da reação, foi realizado primeiramente uma pesquisa prévia de pontos no Distrito Federal que poderiam estar sofrendo com manifestações patológicas.

Logo após essa pesquisa inicial, foram realizadas inspeções preliminares nas diversas estruturas previamente selecionadas e em seguida foram feitas análises visuais e das condições para possível ocorrência da reação álcaliagregado.

Com a seleção de estruturas que tem possibilidade de serem afetadas pela reação álcali-agregado, foram retiradas amostras no concreto para posterior análise por meio do método colorimétrico e com o uso do Microscópio Eletrônico de Varredura (MEV). Abaixo estão os locais das quais foram retiradas amostras para o uso nesse trabalho:

- Ponte das Garças;

- Ponte Costa e Silva;

- Viaduto no Eixo W sobre a Via N2;

- Viaduto no Eixo L na altura da $215 / 216 \mathrm{~N}$;

- Viaduto no Eixo L na altura da 215/216S;

- Viaduto no Eixão Sul sobre a Galeria dos Estados;

- Viaduto sob a Av. Elmo Serejo em Taguatinga;

- Viaduto de pedestres na EPTG próximo a residência oficial de Águas Claras;

- Viaduto de pedestres na EPNB;

- Viaduto no Núcleo Bandeirante;

- Viaduto próx. ao Aeroporto de Brasília;

- Viaduto no Park Way;

- Viaduto no SIA;

- Viaduto BRT Sul;

- Papa-Entulho no Guará e Taguatinga;

- Bloco de Concreto em Águas Claras;

- Prédios abandonados em Águas Claras 1;

- Prédios abandonados em Águas Claras 2;

- Prédio abandonado no Plano Piloto;

- Fábrica da Itambé no SIA;

- Pontos de ônibus no Areal;

- Pontos de ônibus no Pistão Sul e Norte;

- Pontos de ônibus na EPNB;

- Hospital Abandonado na 713 Sul;

- Hospital Abandonado no Setor Hoteleiro Norte;

Após a coleta, as amostras foram levadas para o laboratório onde foi realizado o ensaio pelo método colorimétrico para identificação da RAA. Inicialmente foi preparada uma solução aquosa para cada um dos reagentes, depois foi necessário preparar a superfície da amostra de concreto, sendo a superfície de cada amostra enxaguada com água pura e removido qualquer poeira sobre o concreto. Foi aplicado primeiramente a solução de cobaltonitrito de sódio na superfície do concreto, deixando-o atuar por 30 a 60 segundos, depois desse tempo enxaguou-se a superfície tratada com água pura. Nessa fase será possível observar regiões com coloração amarelada, indicando a presença de potássio solúvel. Em seguida, aplicou-se o segundo reagente (rodamina B), deixando-o agir por 30 a 60 segundos na superfície e lavando-o em seguida com água pura (GUTHRIE; CAREY, 1999). 
Figura 5 - Etapas de impregnação dos reagentes utilizando o método da mancha: (1) - cobaltonitrito de sódio; (2) rodamina b e por fim (3) - constatação da RAA.

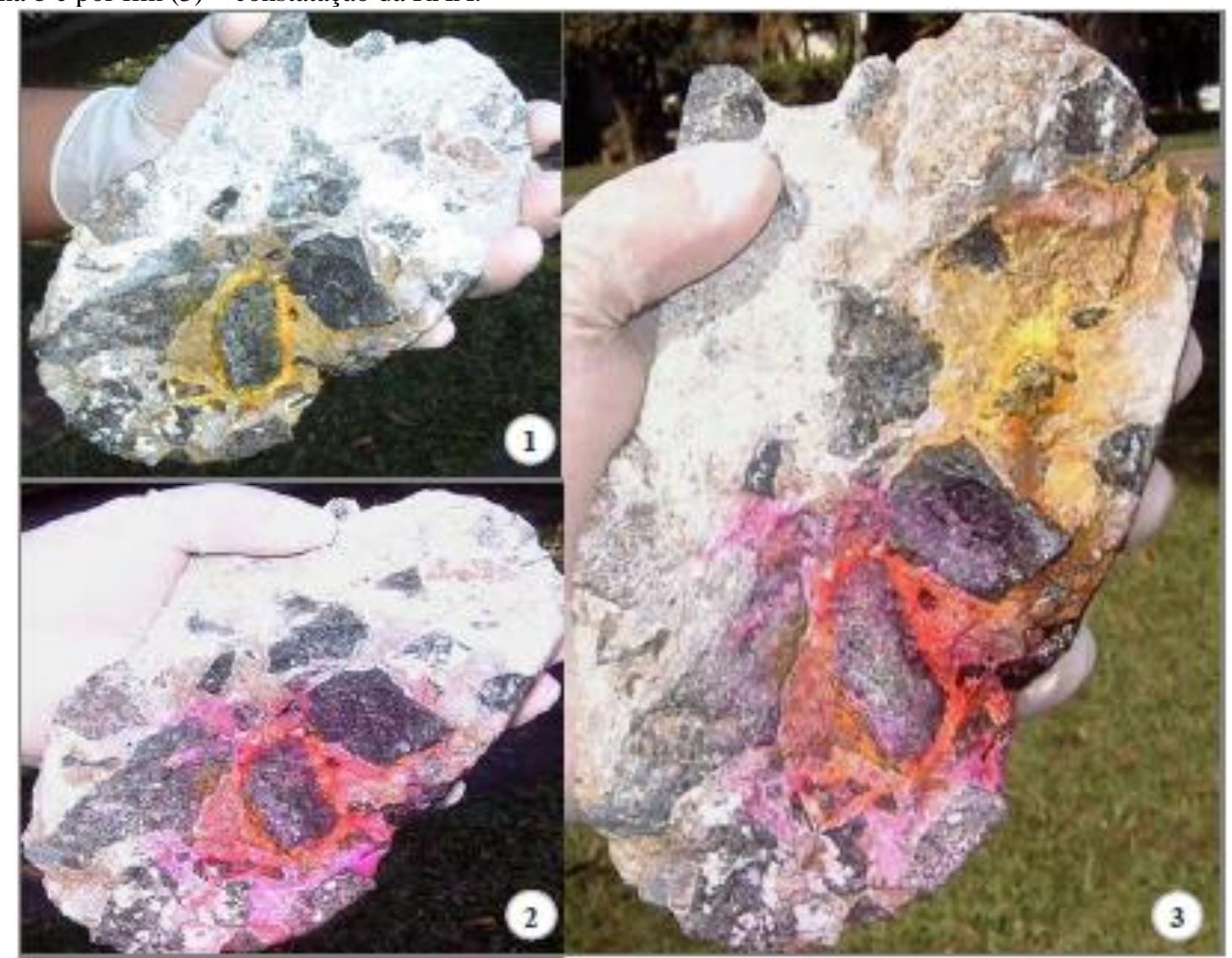

Fonte: (MIZUMOTO, 2009)

Para as análises das amostras de concreto foi utilizado o Microscópio Eletrônico de Varredura (marca: JEOL, modelo: JSM-7001F) do Laboratório de Microscopia e Microanálise da UnB, que possibilita investigar amostras através da produção de imagens com altíssima resolução e detalhar as características microestruturais das amostras, foram feitas microanálises qualitativas dos géis. Das amostras coletadas anteriormente, foram escolhidas 3 que visualmente pareciam apresentar o gel característico da RAA e dessas 3 amostras foram retiradas fragmentos com diâmetros de aproximadamente $3 \mathrm{~cm}$, isso ocorreu pois no $\mathrm{MEV}$ só era permitido fragmentos com até $3 \mathrm{~cm}$ para análise no equipamento. Em seguida, os fragmentos da amostra foram submetidos ao processo de metalização (procedimento realizado para preparar as amostras para uso no MEV) utilizando um equipamento de metalização de amostras (marca: LEICA, modelo: EM SCD 500) e posteriormente seria feito a análise dos fragmentos de amostra utilizando o MEV. 


\section{СВРАT 2020 \\ CONGRESSO BRASILEIRO DE PATOLOGIA DAS CONSTRUÇÕES \\ DE 15 A 17 DE ABRIL | FORTALEZA - CE \\ ISBN 978-65-86819-05-2

Figura 6 - Metodologia utilizada para identificar a presença de reação álcali-agregado em amostras do Distrito Federal.

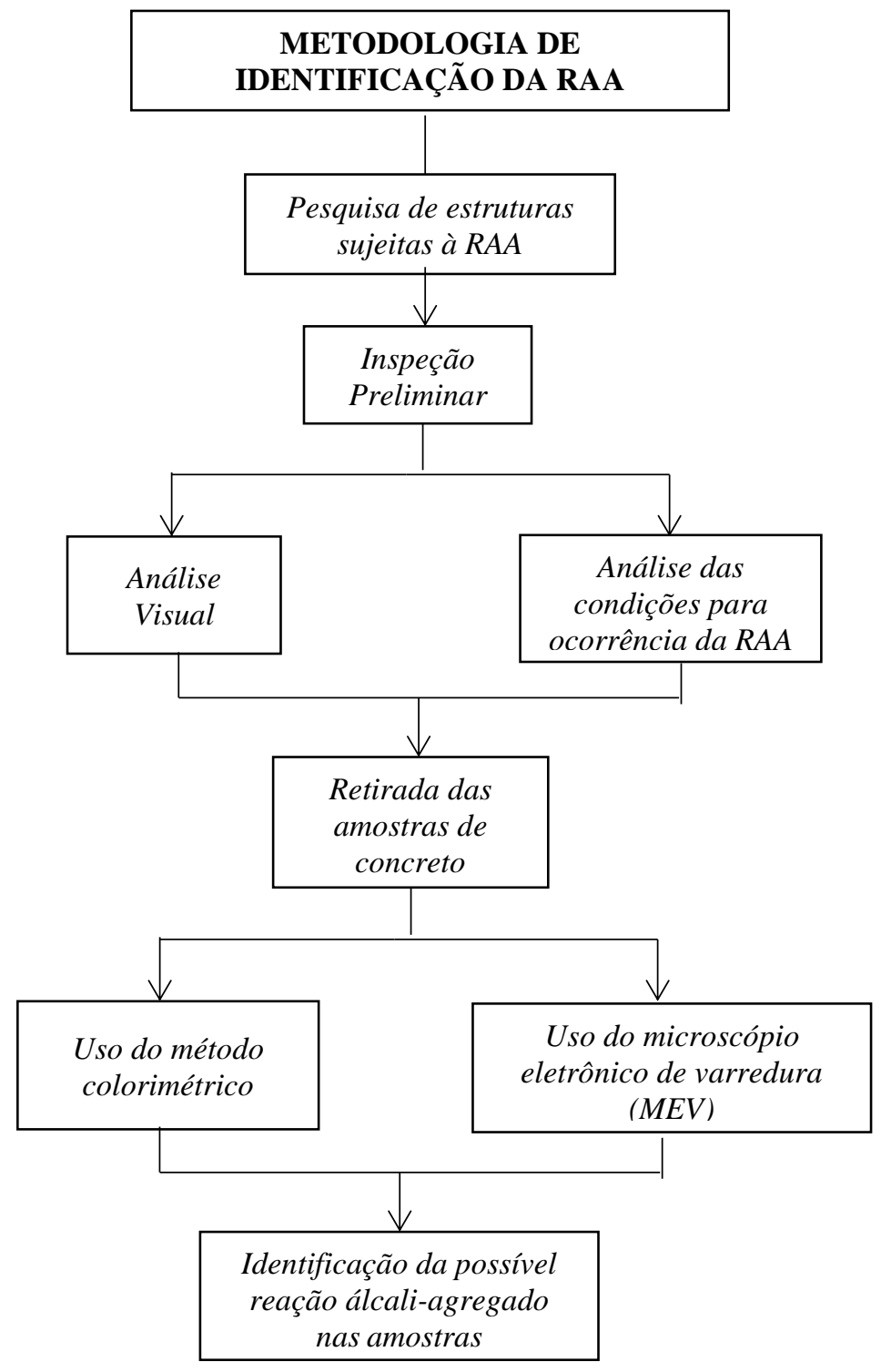

Fonte: Próprio Autor (2019).

\section{RESULTADOS E DISCUSSÃO}

Após a coleta de amostras de concreto em inúmeros locais do Distrito Federal, as amostras foram submetidas as análises utilizando o Método Colorimétrico e o Microscópio Eletrônico de Varredura.

\subsection{Método Colorimétrico}

Foi preparado as amostras com uma limpeza da superfície com água e em seguida cada uma das amostras foram impregnadas inicialmente com uma solução aquosa de Cobaltonitríto de Sódio e depois com o reagente Rodamina B. 


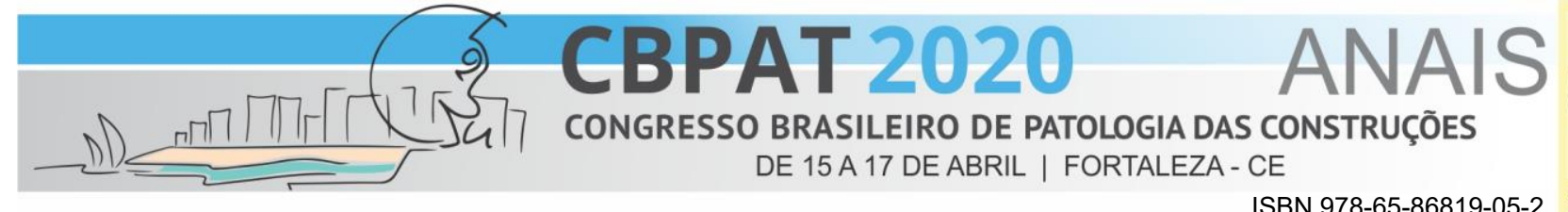

ISBN 978-65-86819-05-2

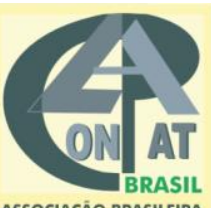

Associacio BRASIL ASSOCIACAO BRASLLILA
DE PATOLOGIADAS CONSTRUÇOES

Figura 7 - Amostra A12 submetida ao método colorimétrico.

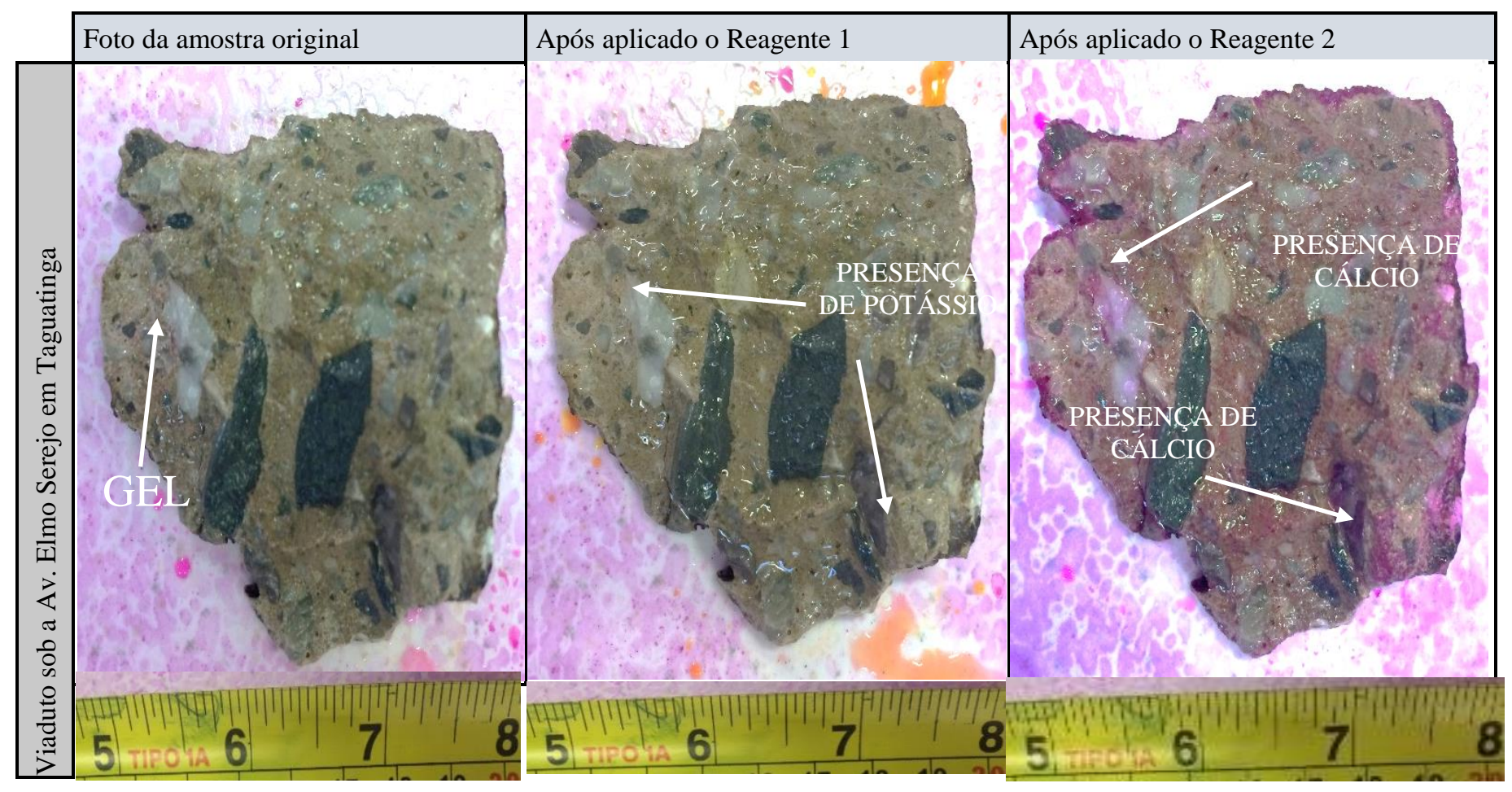

Fonte: Próprio Autor (2019).

Após a aplicação do primeiro reagente (cobaltonitrito de sódio) na amostra original é possível notar que em alguns pontos prevaleceu a coloração alaranjada e depois de lavar a amostra e aplicar o segundo reagente (rodamina b) estes mesmos pontos que estão próximos a agregados graúdos ficaram com coloração rosa indicando que há reação álcaliagregado nesta amostra específica.

Figura 8 - Amostra A3 submetida ao método colorimétrico.

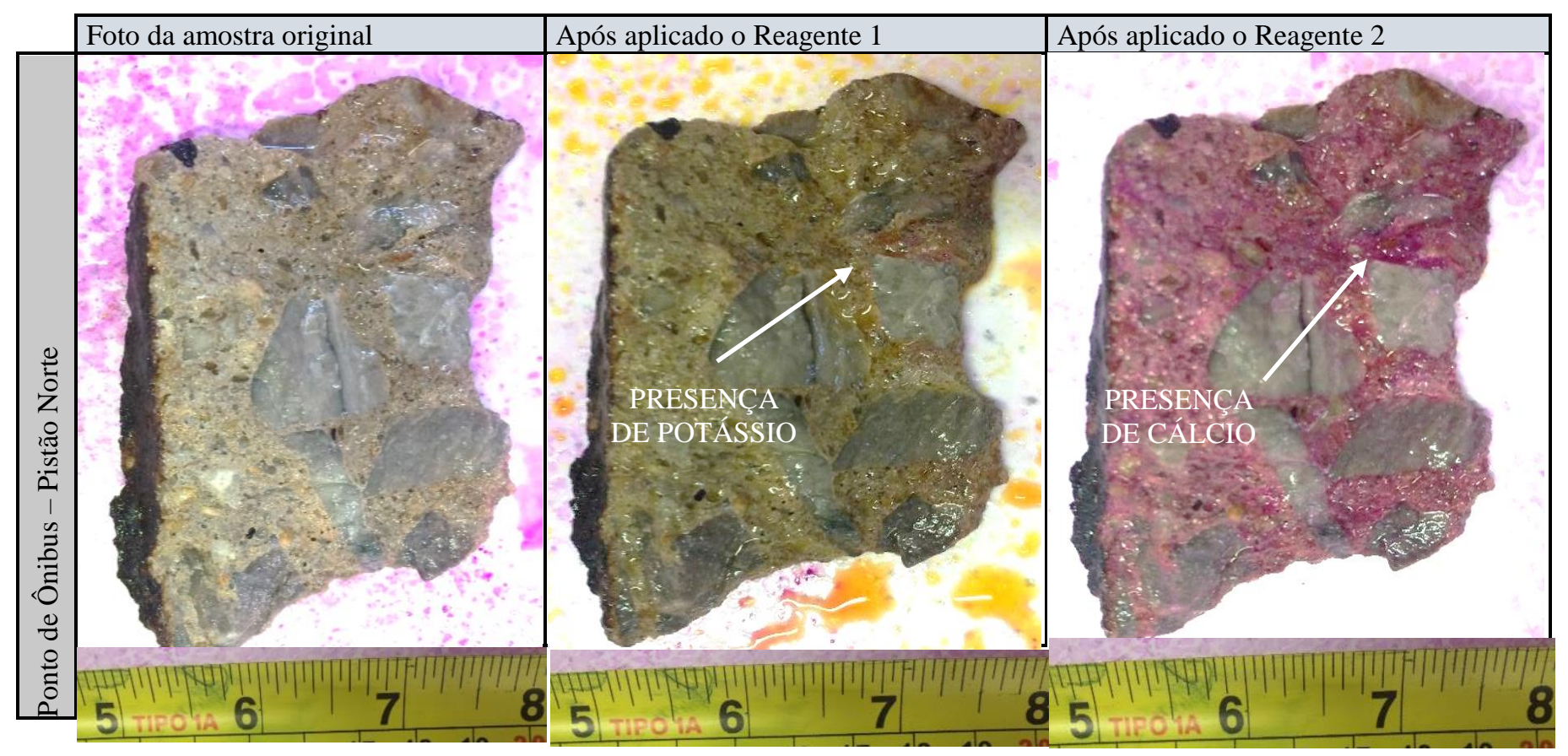

Fonte: Próprio Autor (2019). 


\section{CBPAT 2020 \\ concerss a ass \\ DE 15 A 17 DE ABRIL | FORTALEZA - CE}

As fotos acima são provenientes da fundação do ponto de ônibus do Pistão Norte e nelas é possível identificar que após aplicado o primeiro reagente há um ponto se destaca na imagem com uma cor mais alaranjada devido a reação do reagente cobaltonitrito de sódio com o potássio presente naquele ponto. Depois de aplicar o segundo reagente e esperar reagir com o composto, percebemos que tinha um ponto que estava mais avermelhado que o resto e foi constatado por comparação com a foto da impregnação do primeiro reagente que era o mesmo ponto, mostrando que também há presença de cálcio naquele mesmo ponto. Isso mostra que há presença de RAA nessa amostra.

A reação álcali-agregado dessa amostra foi confirmada usando o $\mathrm{MEV}$, foi possível perceber a presença de cristais típicos formados pela RAA.

Figura 9 - Amostra A6 submetida ao método colorimétrico.

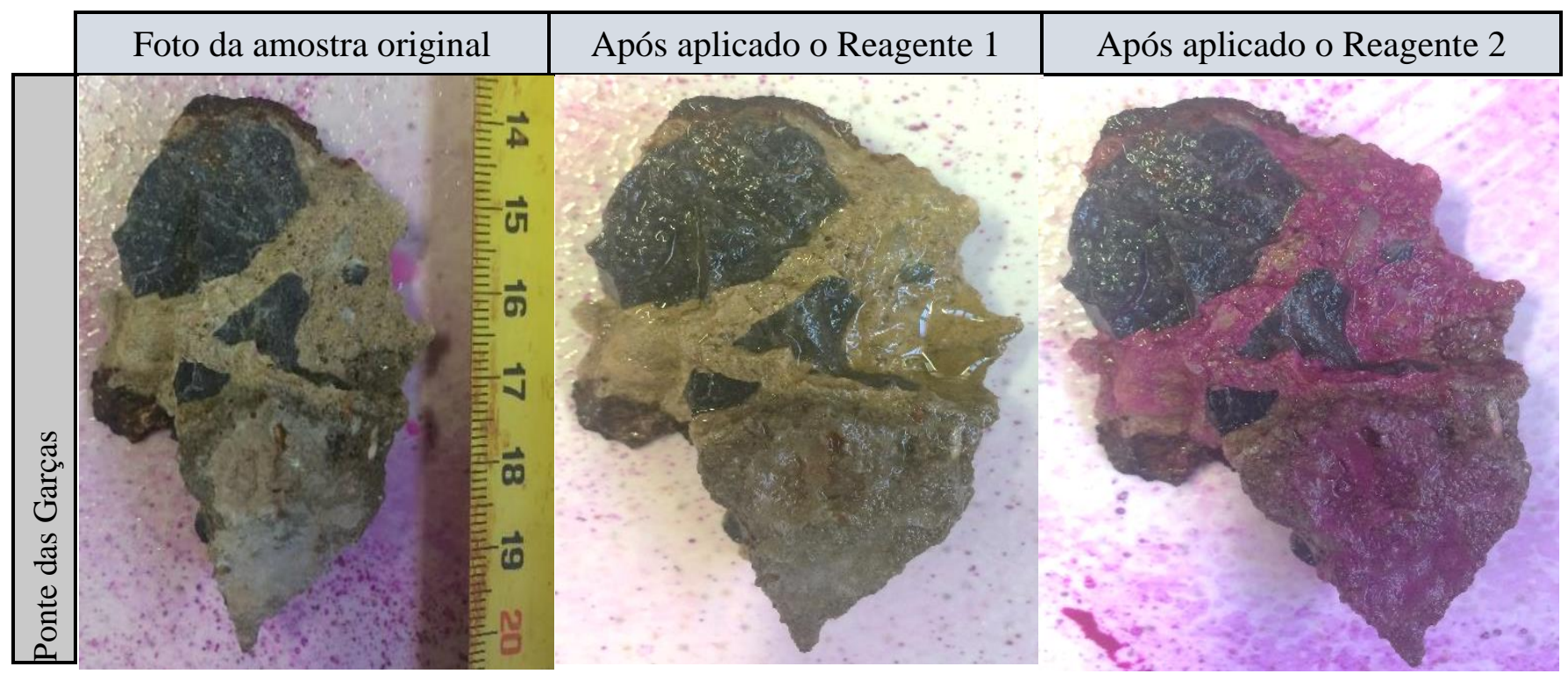

Fonte: Próprio Autor (2019).

Figura 10 - Amostra A16 submetida ao método colorimétrico.

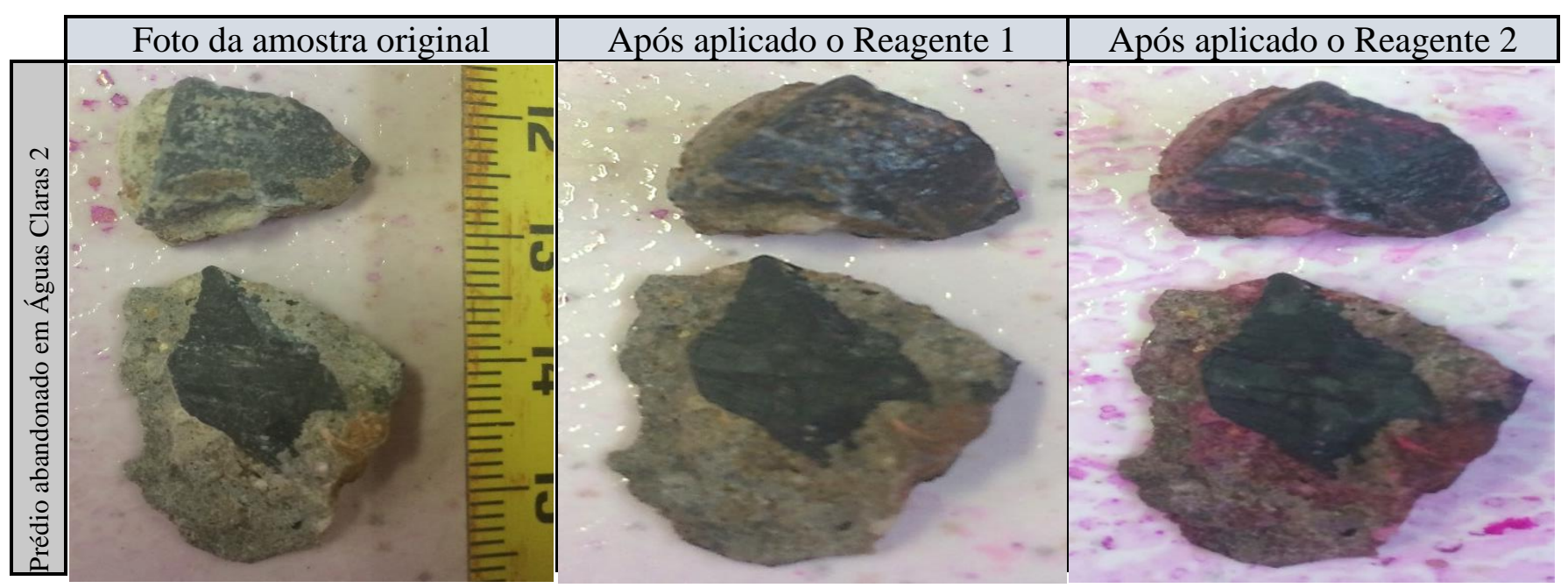

Fonte: Próprio Autor (2019).

Nas imagens acima de amostras de concreto retiradas da Ponte das Garças em Brasília e do Prédio Abandonado em Águas Claras, não é possível identificar nenhum ponto específico que há uma mudança de coloração após aplicado o reagente 1 (cobaltonitrito de sódio) e após a aplicação do reagente 2 (rodamina B) as imagens mostram que nenhum ponto específico têm a presença de cálcio. Posteriormente, usando o MEV foi possível constatar que de fato as amostras de concreto coletadas nesses dois pontos diferentes não apresentavam reação álcali-agregado. Na tabela 1 abaixo está 
indicado todas as amostras que foram constatadas reação álcali-agregado e se houve reação dos reagentes com as amostras para um mesmo ponto.

Tabela 1 - Resultado da impregnação com os reagentes nas amostras de concreto.

\begin{tabular}{|c|c|c|c|c|c|}
\hline & & & Impregnação & dos reagentes & \\
\hline Amostra & Procedência & Dia de coleta & \begin{tabular}{|l|}
$\mathrm{Na} 3[\mathrm{Co}(\mathrm{NO} 2) 6]$ \\
(Cobaltonitrito de \\
Sódio)
\end{tabular} & $\begin{array}{l}\mathrm{C} 28 \mathrm{H} 31 \mathrm{ClN} 2 \mathrm{O} 3 \\
\text { (Rodamina B) }\end{array}$ & $\begin{array}{l}\text { Constatação } \\
\text { da RAA }\end{array}$ \\
\hline A1 & Fábrica da itambé no SIA & $05 / \mathrm{abr}$ & NR & NR & A \\
\hline $\mathrm{A} 2$ & Ponto de ônibus no pistão sul & $28 / \mathrm{abr}$ & NR & $\mathrm{R}$ & $\mathrm{A}$ \\
\hline A3 & Ponto de ônibus no pistão norte & $25 / \mathrm{abr}$ & $\mathrm{R}$ & $\mathrm{R}$ & $\mathrm{P}$ \\
\hline A4 & Ponto de ônibus na EPNB & 27/mai & NR & NR & $\mathrm{A}$ \\
\hline A5 & Ponto de ônibus no Areal & $25 / a b r$ & NR & NR & $\mathrm{A}$ \\
\hline A6 & Ponte das Garças & $31 / \mathrm{mar}$ & NR & NR & A \\
\hline A7 & Ponte Costa e Silva & $31 / \mathrm{mar}$ & NR & NR & A \\
\hline A8 & Viaduto do Eixo W sobre a via N2 & $25 / a b r$ & $\mathrm{R}$ & $\mathrm{R}$ & $\mathrm{P}$ \\
\hline A9 & Viaduto do Eixo L - 215/216S & $26 / a b r$ & NR & NR & $\mathrm{A}$ \\
\hline A10 & Viaduto do Eixo L - 215/216N & $26 / a b r$ & NR & NR & $\mathrm{A}$ \\
\hline A11 & $\begin{array}{l}\text { Viaduto do Eixo Eixão sobre a Galeria dos } \\
\text { Estados }\end{array}$ & 04/mai & NR & NR & A \\
\hline A12 & $\begin{array}{l}\text { Viaduto sob a Av. Elmo Serejo em } \\
\text { Taguatinga }\end{array}$ & 05/mai & $\mathrm{R}$ & $\mathrm{R}$ & $\mathrm{P}$ \\
\hline A13 & Viaduto de pedestre na EPTG & 04/mai & NR & NR & $\mathrm{A}$ \\
\hline A14 & Viaduto de pedestre na EPNB & 04/mai & NR & NR & $\mathrm{A}$ \\
\hline A15 & Prédio abandonado em Águas Claras 1 & 05/mai & $\mathrm{R}$ & $\mathrm{R}$ & $\mathrm{P}$ \\
\hline A16 & Prédio abandonado em Águas Claras 2 & 05/mai & NR & NR & $\mathrm{A}$ \\
\hline A17 & Prédio abandonado no Plano Piloto & $11 /$ mai & NR & $\mathrm{R}$ & $\mathrm{A}$ \\
\hline A18 & Papa entulho no Guará & $27 / \mathrm{mai}$ & NR & $\mathrm{R}$ & A \\
\hline A19 & Papa entulho no Taguatinga & $27 /$ mai & $\mathrm{R}$ & $\mathrm{R}$ & $\mathrm{P}$ \\
\hline $\mathrm{A} 20$ & Hospital abandonado na $713 \mathrm{Sul}$ & $30 / \mathrm{mar}$ & $\mathrm{R}$ & $\mathrm{R}$ & $\mathrm{P}$ \\
\hline A21 & Hotel abandonado no st hoteleiro norte & $30 /$ mar & NR & $\mathrm{R}$ & A \\
\hline A22 & Viaduto no Núcleo Bandeirante & 19/mai & NR & $\mathrm{R}$ & $\mathrm{A}$ \\
\hline A23 & Viaduto próx. Ao Aeroporto de Brasília & 19/mai & $\mathrm{R}$ & $\mathrm{R}$ & $\mathrm{P}$ \\
\hline A24 & Viaduto do BRT Sul & 19/mai & NR & NR & $\mathrm{A}$ \\
\hline $\mathrm{A} 25$ & Viaduto no Park Way & 19/mai & NR & NR & A \\
\hline A26 & Viaduto no SIA & 19/mai & NR & NR & A \\
\hline A27 & $\begin{array}{l}\text { Amostra de bloco de concreto em Águas } \\
\text { Claras }\end{array}$ & 05/mai & NR & $\mathrm{R}$ & A \\
\hline
\end{tabular}

Legenda:

A - Ausência da RAA, P - Presença da RAA.

$\mathbf{R}$ - Reação do reagente com a amostra, NR - Não ocorreu reação do reagente com a amostra. 


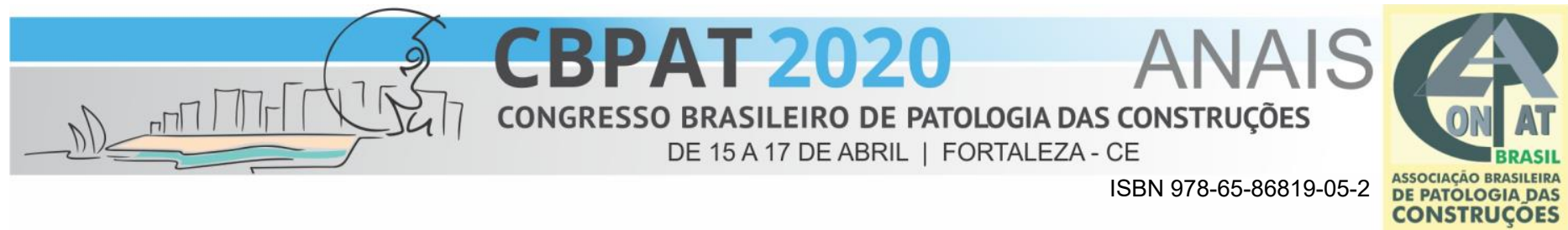

\subsection{Análise com o Microscópio Eletrônico de Varredura}

A análise com o MEV foi realizada no Laboratório de Microscopia e Microanálise da UnB. Foram preparadas 3 amostras de concreto com maior possibilidade de ocorrência da reação álcali-agregado para ser analisada utilizando o microscópio.

Figura 11 - Amostras submetidas a ao MEV.

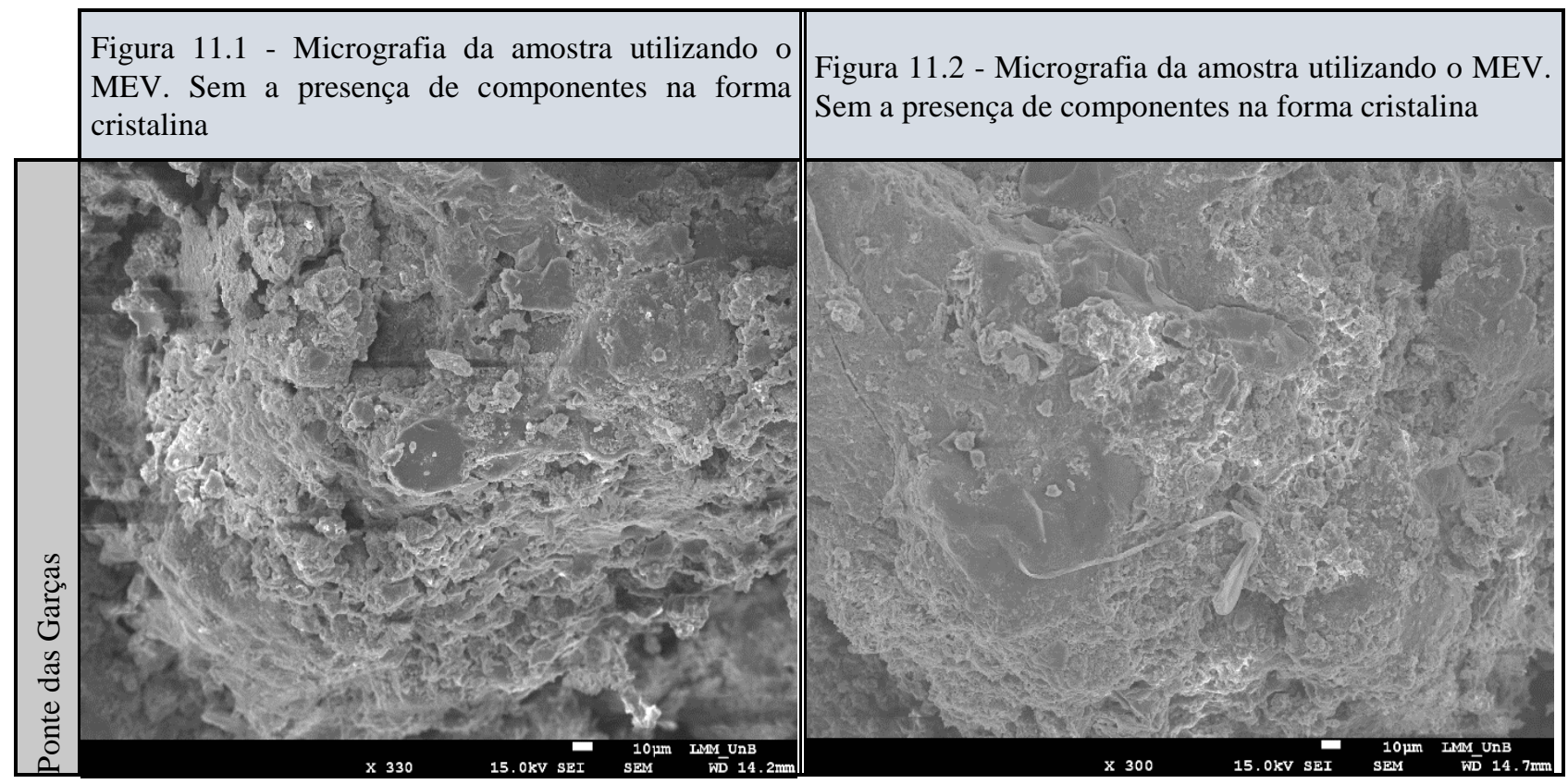

Figura 11.3 - Micrografia da amostra utilizando o MEV. Presença de cristais típicos formados pela Reação Álcali-Agregado.

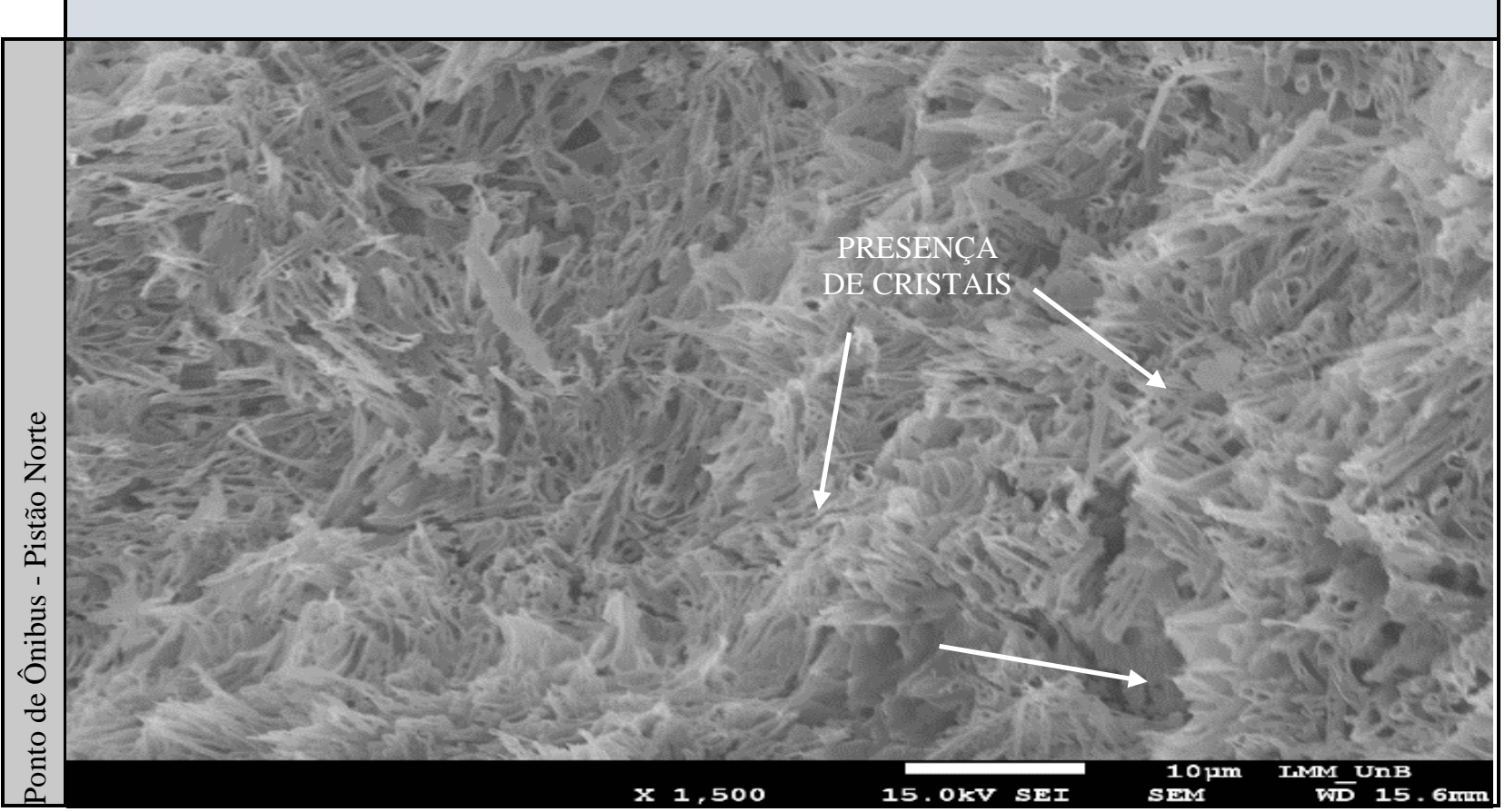




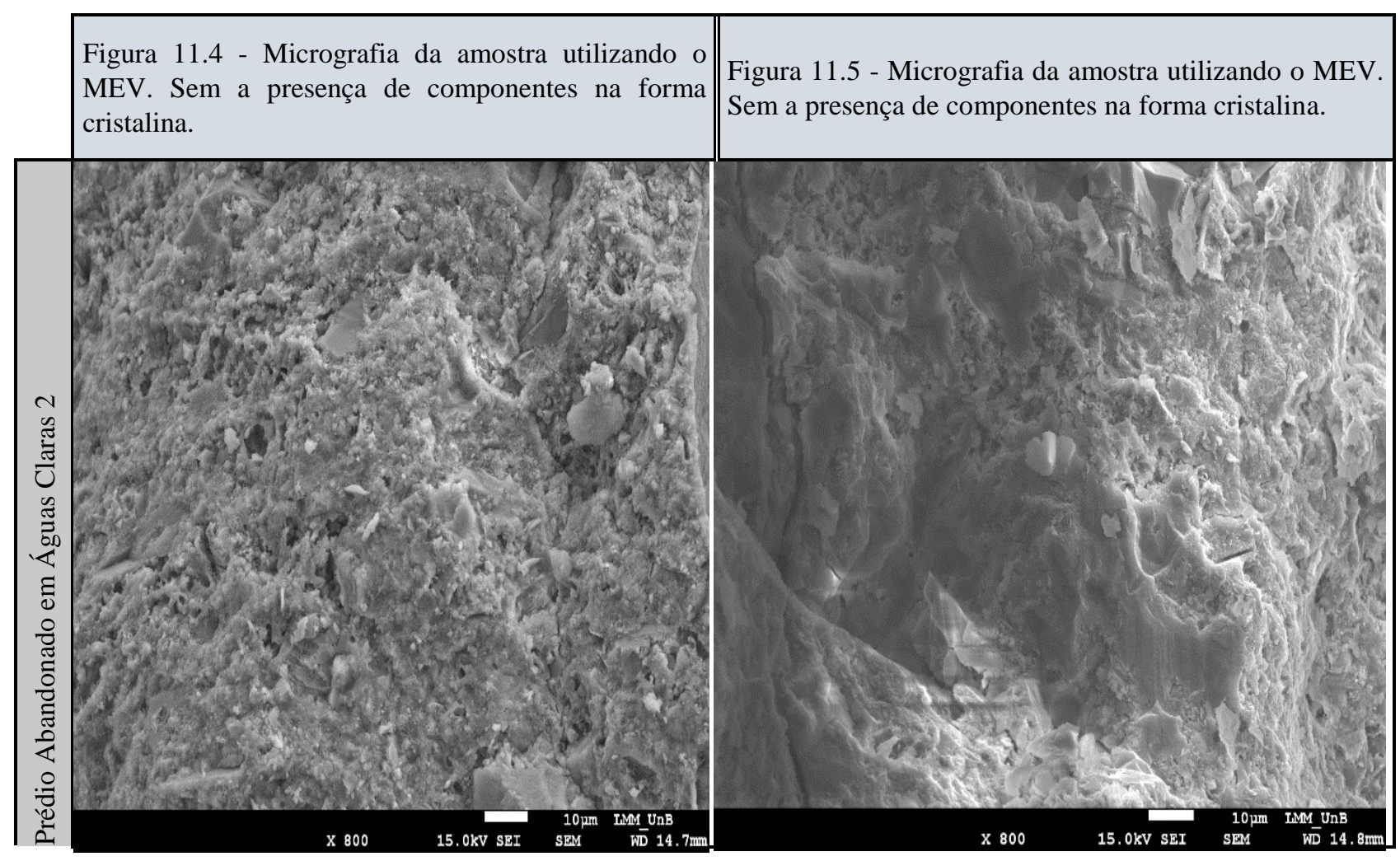

Fonte: Próprio Autor (2019).

\section{CONCLUSÃO}

O método colorimétrico utilizado no trabalho possibilita uma identificação qualitativa da reação álcali-agregado e em várias amostras é possível fazer uma análise visual e constatar o gel esbranquiçado típico da RAA e posteriormente usando o método colorimétrico foi possível constatar que aquele gel identificado por análise visual é proveniente da RAA.

Contudo, o uso desse método nas amostras realizadas nesse trabalho mostrou imprecisão em alguns momentos com o uso do reagente Rodamina B pois este reagente reagiu com outros componentes das amostras manchando com a cor rosa e dificultando na identificação dos pontos específicos que houve reação dos dois reagentes. Assim apesar desse método ser útil para uma análise qualitativa em campo, pode apresentar dificuldades na interpretação dos resultados pois assim como ocorreu em diversas amostras desse trabalho os reagentes empregados podem reagir com outros componentes e dificultar a constatação da RAA.

$\mathrm{O}$ uso do MEV para constatação de reação álcali-agregado se mostrou mais assertivo pois mostra com clareza os cristais formados pela RAA, porém como o acesso a um MEV é muito restrito, por ser um equipamento com valor agregado muito elevado, é quase que inviável o seu uso para a constatação de RAA em um número considerável de amostras. No aspecto de viabilidade e custo, o uso do método colorimétrico tem ótimo desempenho pois é um método que pode ser usado em campo e tem baixo custo. Entretanto, se o objetivo for assertividade e um diagnóstico preciso sem levar em conta fatores econômicos, a alternativa é utilizar o MEV para identificar a reação álcali-agregado.

Dentre as 27 amostras de diversas estruturas do DF estudadas, em 7 delas o uso do método colorimétrico identificou que estava ocorrendo RAA, aproximadamente em 1/4 das amostras, sendo que na amostra A3, retirada no ponto de ônibus do pistão norte foi possível confirmar que há presença de RAA com o uso do MEV. 


\section{REFERÊNCIAS}

[1] SIMS, Ian; POOLE, Alan. Alkali-Aggregate Reaction in Concrete: A World Review. London: Crc Press, 2017.

[2] STAnTON, Thomas E.. Expansion of Concrete Through Reaction Between Cement and Aggregate. 66. ed. California: American Society Of Civil Engineers, 1940.

[3] HASPARYK, Nicole Pagan. Investigação de concretos afetados pela reação álcali-agregado e caracterização avançada do gel exsudado. 2005. 326 f. Tese (Doutorado) - Curso de Engenharia Civil, Universidade Federal do Rio Grande do Sul, Porto Alegre, 2015. Disponível em: <https://www.lume.ufrgs.br/handle/10183/6350>. Acesso em: 25 mar. 2019.

[4] HELENE, Paulo R. L. Vida útil das estruturas de concreto. São Paulo: USP/ Departamento de Engenharia Civil, 2003b. p. 4. Disponível em: 〈http://www.alconpat.org.uy/doc/biblio/helene.pdf>. Acesso em: 02 abril. 2019.

[5] UNITED STADES PATENT (Estados Unidos). George D. Guthrie, Jr.; William Carey. Detection of alkali-silica reaction swelling in concrete by staining. US $n^{\circ}$ 5,955,372, 14 abr. 1998, 21 set. 1999. 1999.

[6] MIZUMOTO, Camilo. Investigação da Reação Álcali-Agregado (RAA) em Testemunhos de Concreto e Agregados Constituintes. 2009. 162 f. Dissertação (Mestrado) - Curso de Engenharia Civil, Unesp, Ilha Solteira, 2009.

[7] GUTHRIE, G. D.; CAREY, J. W. A geochemical method for the identification of ASR gel. [S.1.]: TRB, 1999. p. 7. 1 CD ROM.

[8] COLLINS, C. et al. Alkali-silica reaction the cancer of concrete. Disponível em: <https://slideplayer.com/slide/3876748/>. Acesso em: 13 abril. 2019.

[9] SILVEIRA, Ana Lívia Zeitune de Paula. Estudo de Reação Álcali-Agregado em Rochas Carbonáticas. 2006.166 f. Dissertação (Mestrado) - Instituto de Geociências, Universidade de Brasília, Brasília, 2006.

[10] COUTO, Tiago Andrade. Reação Álcali-Agregado - Estudo do fenômeno em rochas silicosas. $2008.191 \mathrm{f}$. Dissertação (Mestrado) - Curso de Engenharia Civil, Universidade Federal de Goiás, Goiânia, 2008. 